\title{
Produções sobre educação inclusiva: o ensino superior em foco
}

\author{
Carla Pacheco Govêa ${ }^{1}$ \\ Claudia Gomes ${ }^{2}$
}

\section{Resumo}

No que diz respeito à inclusão de pessoas com deficiência no ensino superior, observam-se estudos sistematizados que buscam oferecer um panorama da efetivação do processo de inclusão. A partir disso, este trabalho teve o objetivo de caracterizar a produção cientifica voltada à inclusão de estudantes com deficiência no contexto de democratização do ensino superior. Para tanto, realizamos uma revisão de literatura no banco de dados do SciELO (de 2007 a 2017) e selecionamos 48 artigos conforme os descritores "inclusão", "ensino superior" e "deficiência". Ressalta-se que os artigos pesquisados fazem menção à modalidade de ensino presencial. No geral, os trabalhos apontam a necessidade de reconstrução do sistema de ensino superior para superação de barreiras e de investimento em ações que problematizem o preconceito e favoreça a autonomia e a cidadania.

Palavras-chave: Inclusão; Ensino Superior; Pessoa com Deficiência.

\section{Inclusive education text productions: focus on higher education}

\begin{abstract}
Systematic studies that offer an overview of effectiveness of inclusion process discuss inclusion of people with disabilities in higher education. Thus, this work aimed to characterize scientific production related to including students with disabilities in the context of democratization on higher education. Therefore, we performed a literature review in the SciELO database (from 2007 to 2017) and selected 48 articles according to the descriptors "inclusion", "higher education" and "disability". It is noteworthy that the researched articles mention classroom teaching modality. Overall, this work points to the need to rebuild the higher education system to overcome barriers, besides invest in actions that problematize prejudice and favor autonomy and citizenship.

Keywords: Speech; Inclusion; Higher Education; Disabled Person.
\end{abstract}

\section{Introdução}

A proposta de educação inclusiva aponta para um momento crucial de se repensar velhos paradigmas na educação e na sociedade, à medida que institui como imperativo políticas e práticas educativas pautadas na democracia, na igualdade de direitos e no respeito à diversidade humana. Ao tomar forma no Brasil a partir da década de 1990, a perspectiva inclusiva legitimouse por preceitos legais de âmbito internacional que prescreveram e influenciaram as políticas e legislações referentes à educação no âmbito nacional. Tal perspectiva apresenta um discurso

\footnotetext{
${ }^{1}$ Instituto Federal Sul de Minas, Inconfidentes, carla.pacheco@ifsuldeminas.edu.br

${ }^{2}$ Universidade Federal de Alfenas, Alfenas, cg.unifal@gmail.com
} 
que privilegia a diversidade humana e a igualdade de direitos, trazendo à tona documentos legais que asseguram o acesso e a permanência de pessoas com deficiência, tanto na educação básica como no ensino acadêmico - antes negado a esses sujeitos.

No cenário internacional, as conferências que recebem destaque, dada a incorporação de seus princípios nos sistemas educacionais dos países signatários, são: a) a Conferência Mundial sobre Educação para Todos, ocorrida na Tailândia em 1990; b) a Conferência Mundial sobre Necessidades Educativas Especiais, no ano de 1994, em Salamanca, emanando a Declaração de Salamanca; e c) Conferência Internacional sobre Educação da UNESCO 2008, em Genebra.

Assim, com repercussão direta na educação das pessoas com necessidades educacionais especiais, as conferências internacionais estabeleceram o compromisso mundial de educar todos, reafirmando a necessidade de garantir educação para as crianças, jovens e adultos com necessidades educativas especiais no sistema regular de ensino, até tomar a educação inclusiva como um dos seus grandes temas (MOREIRA; BOLSANELLO; SEGER, 2011).

Enquanto signatário das conferências internacionais, o Brasil tem como decorrência direta a incorporação de seus princípios nos sistemas educacionais. Dessa forma, no âmbito nacional, os documentos que respaldam a perspectiva da educação inclusiva no contexto geral são: Constituição Federal (BRASIL, 1988), Estatuto da Criança e do Adolescente (BRASIL, 1990), Lei de Diretrizes e Bases da Educação (BRASIL, 1996), Plano Nacional de Educação (BRASIL, 2001), Política Nacional de Educação Especial na Perspectiva Inclusiva (MINISTÉRIO DA EDUCAÇÃO, 2008) e, mais recentemente, Lei Brasileira de Inclusão da Pessoa com Deficiência (BRASIL, 2015).

Nesse contexto, o movimento pela inclusão de estudantes com deficiência no ensino superior, assim como na educação básica, começa a emergir por meio do aparato legal na década de 1990, mas podem ser citados como mais recentes: o Decreto no 7.611 de 2011, que garante o apoio do governo federal na estruturação dos núcleos de acessibilidade nas Instituições de Ensino Superior (IES); e a Lei no 13.409 de 28 de dezembro de 2016, que dispõe sobre a reserva de vagas para pessoas com deficiência nos cursos técnicos de nível médio e superior das instituições federais de ensino.

Verifica-se, a partir da década de 1990, que o sistema educacional brasileiro se encontra legalmente amparado pela perspectiva dos preceitos inclusivos, pautados nos princípios 
democráticos de igualdade, equidade e diversidade. No entanto, Beyer (2011) sinaliza que, diferente de muitos países onde os dispositivos legais foram se constituindo gradativamente - à medida que as experiências de inclusão se desenvolviam e provocavam as demandas dos grupos no sentido do projeto ser acolhido pela legislação educacional -, no Brasil, o ponto crítico de nossa experiência deve-se à inversão desse processo. Ou seja, a legislação avançou, acompanhando o paradigma inclusivo, antes das escolas e sistemas educacionais vivenciarem suas experiências de inclusão dos estudantes com necessidades educacionais especiais. Assim, para o autor, "estamos diante da demanda que resulta da priorização em lei do projeto políticopedagógico inclusivo, e que não nos possibilita, ainda, formas exequíveis de implantação" (BEYER, 2011, p.81).

Nesse sentido, apresentando inequívoco reconhecimento da necessidade e importância de tais documentos, autores como Gomes, Bazon e Lozano (2015), Orrú (2016) e Rossetto (2009) nos trazem a ideia de que o aparato legal que constitui a defesa de direitos não representa uma conversão direta em práticas sustentadas pelo respeito à diferença e à valorização da pessoa humana, no cotidiano do espaço de formação. Apontamentos no sentido de que a legislação, por si só, não garante que o direito ao acesso e à permanência, tal como definido pelos documentos nacionais e internacionais, esteja realmente sendo efetivado, havendo, assim, um distanciamento entre a lei e a prática. Nessa perspectiva, "a jurisprudência se mostra mais importante em seu acontecimento do que as próprias leis. Ela se abastece e se constitui não pelo complexo de leis maiores, mas sim pelos acontecimentos menores, particulares singulares" (ORRÚ, 2016, p.49).

Para Moreira, Bolsanello e Seger (2011), em relação à educação de pessoas com deficiência, o cenário de exclusão é mais evidente, sendo possível constatar que há um vazio histórico relacionado às políticas públicas direcionadas a esse segmento; motivo pelo qual as referidas autoras consideram que o processo de inclusão dessas pessoas, alavancado nas últimas décadas, faz jus a uma análise cuidadosa. Dessa forma, atentam para a questão de que, assim como na educação básica, a proposta da inclusão de estudantes com deficiência no ensino superior demanda planejamento pedagógico, com financiamento que possa assegurar os apoios e recursos materiais, físicos e humanos necessários à formação de qualidade destes estudantes. 


\section{Pensando a Democratização do Ensino Superior}

Pensar essas questões nos remete ao processo de democratização do ensino superior brasileiro. Nesse sentido, chamando atenção para a notável expansão do sistema educacional superior nas últimas décadas, Sobrinho (2010) ressalta que essa expansão se deu principalmente pela via privada, com o crescimento de $100 \%$ desse setor na década de 2000 , contra $40 \%$ do setor público. De acordo com os dados do Instituto Nacional de Estudos e Pesquisas Educacionais Anísio Teixeira (INEP) é ainda significativa a disparidade entre o número de matrículas no ensino superior, com percentual de $75,3 \%$ nas instituições privadas e $24,4 \%$ na rede pública de ensino (BRASIL, 2016). Quanto ao número de matrículas de pessoas com deficiência no ensino superior, os referidos dados registram um total de 35. 891 em 2016. No entanto, observa-se que do total de 8.052.254 estudantes matriculados no ensino superior, apenas $0,55 \%$ é composto por estudantes com deficiência.

Ao constatarem a ampliação do acesso ao ensino superior a partir dos anos 2000, Gomes, Bazon e Lozano (2015) ressaltam a educação superior como nível relevante para a formação profissional e atuação dos indivíduos na sociedade. Nessa perspectiva, discutindo a implantação dos programas de acessibilidade, Oliveira e Silva (2017) fazem referência ao Programa Universidade para Todos (Prouni), ao Fundo de Financiamento Estudantil (Fies), ao Programa Incluir, às cotas raciais e sociais, ao Plano Nacional de Assistência Estudantil (Pnaes), ao Sistema Universidade Aberta do Brasil, ao Programa de Apoio a Planos de Reestruturação e Expansão das Universidades Federais (Reuni) e demais ações afirmativas.

Nesse contexto, como política de democratização das IES públicas, importante se faz considerar iniciativas como o Reuni. Instituído pelo Decreto n. 6.096/2007, o programa é orientado por objetivos como: redução das taxas de evasão, aproveitamento de vagas ociosas, otimização da mobilidade estudantil, reorganização curricular, diversificação da oferta de cursos de graduação, ampliação de políticas de inclusão e assistência aos estudantes.

Diante do contexto histórico e político em que o ensino superior no Brasil se constituiu enquanto espaço seletivo e excludente, verifica-se um constante tensionamento no sentido de reverter, ou minimizar, as desigualdades sociais que, de maneira dialética, são produzidas/reproduzidas no e pelo espaço acadêmico (ANSAY, 2010). Nesse contexto, podemos 
constatar que a democratização do ensino superior é tema em voga no cenário da educação nacional, cujos preceitos baseiam-se na defesa do direito ao acesso e participação, com equidade e qualidade, de sujeitos historicamente excluídos desse segmento de ensino, dentre estes, os estudantes com deficiência. Assim, verificamos que, além do aparato legal, estão sendo empreendidos estudos sistematizados que buscam oferecer um panorama da efetivação do processo de inclusão.

No entanto, ao considerarem o contexto de desenvolvimento da sociedade capitalista, Michels e Garcia (2014) realizam uma análise do termo "sistema educacional inclusivo", que passou a ser adotado nos referidos documentos normativos, refletindo acerca das significações e implicações políticas de seu uso a partir das contradições sociais. Dessa forma, as autoras ressaltam que:

Se, por um lado, o termo "sistema educacional inclusivo" remete para a ampliação dos direitos e inserção social de grupos historicamente marginalizados, por outro lado, mobiliza sentidos pouco explicitados de incorporação de uma lógica privatista na educação estruturada em dois grandes eixos: o privado mercantil e o privado assistencial (MICHELS; GARCIA, 2014, p.164-165).

Nessa perspectiva, a análise das autoras sinaliza sentidos relacionados ao aprofundamento da privatização da educação brasileira na apropriação política do termo "sistema educacional inclusivo". Nesse contexto, trazendo o reconhecimento de que o Prouni se apresenta como um programa de financiamento público que facilita a ocupação de vagas a estudantes que não teriam condições de acessar instituições privadas, Sobrinho (2010) faz eco a diversos trabalhos que pontuam os limites desse programa.

Um dos pontos apresentados nesses trabalhos traz a reflexão de que o crescimento das vagas oferecidas atende a uma lógica própria de interesse e gestão das IES privadas (NEVES; RAIZER; FACHINETTO, 2007). Outra discussão, possivelmente complementar a análise anterior, aponta o fato de que essa iniciativa contribui para dissimular a real necessidade de investimento maciço em educação pública e de qualidade (SARAIVA; NUNES, 2011). Nesse sentido, encontramos em Sobrinho (2010) a perspectiva de o programa ser focado e emergencial, não alterando, portanto, de maneira significativa os sentidos e estruturas do sistema de educação superior. 
Nesse modelo, em que se estabelece um estreitamento dos laços da universidade com as demandas de mercado, aprofunda-se a tendência de tratar a educação superior como mercadoria, atendendo aos interesses de empresas de ensino. Saviani (2010) defende a necessidade de se rever essa tendência para que a primazia passe das instituições privadas para as públicas, propiciando a formação profissional qualificada pela produção da pesquisa científica na articulação ensino e pesquisa.

Para Saviani (1999), lutar contra tal estrutura significa engajar-se no esforço para garantir um ensino da melhor qualidade possível às camadas populares. Assim, conceituando educação como atividade mediadora no seio da prática social, o autor faz a defesa de que o aprimoramento do ensino à classe dos trabalhadores implica na prioridade de conteúdo, "porque o domínio da cultura constitui instrumento indispensável para a participação política das massas" (SAVIANI, 1999, p.65). Corroborando com a perspectiva, Gomes, Bazon e Lozano (2015) salientam que "a democratização da educação precisa ir além da inserção de alunos em ambientes escolares e universitários, precisa se voltar para as diferentes necessidades dos alunos de forma a oportunizar a participação de todos na apropriação do conhecimento" (GOMES; BAZON; LOZANO, 2015, p.3).

Analisando o processo de transformação do paradigma da inclusão social, Oliveira et al. (2016) pontuam que diversos marcos legais, políticos e pedagógicos são responsáveis por mudanças evolutivas. Em relação à inclusão de pessoas com deficiência no ensino superior, os autores destacam o Programa Incluir do Ministério da Educação que, de 2005 a 2011, buscou promover acessibilidade na educação superior, significando "o início da formulação de estratégias para identificação das barreiras refletidas no acesso das pessoas com deficiência ao ensino superior" (OLIVEIRA et al., 2016, p.308). No referido trabalho, que teve como objetivo a revisão da literatura, os autores fazem a inferência de que a disseminação dessa política pública fomentou as pesquisas sobre a temática que começaram a partir de 2006.

Neste sentido, torna-se imprescindível compreender como a inclusão de pessoas com deficiência no ensino superior vem sendo discutida no campo da produção acadêmica, de maneira que possamos visualizar os aspectos e dimensões privilegiadas na abordagem do tema. 


\section{Procedimentos metodológicos}

A partir de uma revisão sistemática da literatura, o presente estudo tem como delineamento a análise de produções, constituindo-se como pesquisa do estado da arte, de natureza descritiva e paradigma quantitativo. Com isso, busca possibilitar um panorama geral das produções científicas, apontando trajetórias e aspectos abordados sobre a temática da educação inclusiva no ensino superior. De caráter bibliográfico, o estado da arte se configura como um recurso metodológico que visa responder aspectos e contextos pesquisados em épocas e localidades distintas (FERREIRA, 2002; LIMA; MIOTO, 2007; NASCIMENTO; CRUZ; BRAUN, 2017).

Para tanto, delimitamos como campo investigativo o levantamento das produções científicas publicadas em ambiente virtual na base de dados da Scientific Eletronic Library Online (SciELO-Brasil), no período de 2007 a 2017. Este recorte temporal tem presente o marco histórico de um período com investimento significativo na organização da política pública brasileira voltada ao processo inclusivo no ensino superior.

Para localizar as produções, as expressões utilizadas como descritores associados de busca foram: inclusão, ensino superior e deficiência, agregados do operador AND, tendo como filtros o idioma (português) e o ano de publicação. O levantamento das produções disponíveis no banco de dados SciELO derivadas das combinações dos referidos descritores gerou, nessa busca, um total de 93 artigos.

Foram adotados como critérios de inclusão para análise os artigos disponibilizados eletronicamente na íntegra, em língua portuguesa e com foco na abordagem da temática da inclusão no ensino superior. Nesse contexto, após análise dos resumos, considerando objetivo principal de investigação, delineamento e considerações finais, verificamos que quarenta e oito artigos apresentaram pertinência em relação aos critérios de inclusão para análise.

\section{Resultados e Discussões}

Dado mapeamento dos estudos que efetivamente se referiam ao processo inclusivo no ensino superior, a organização das categorias de análise emergiu da tônica discutida nos 
trabalhos selecionados. Assim, a partir da análise das produções científicas selecionadas, foi possível sistematizar os estudos em cinco categorias temáticas, a saber: a) Políticas de acesso à universidade; b) Democratização do ensino superior; c) Condições de acessibilidade; d) Formação voltada à educação inclusiva; e) Concepções dos docentes. Assim, a sistematização das referidas categorias encontra-se representada no gráfico a seguir.

Gráfico - Categorização temática dos artigos encontrados

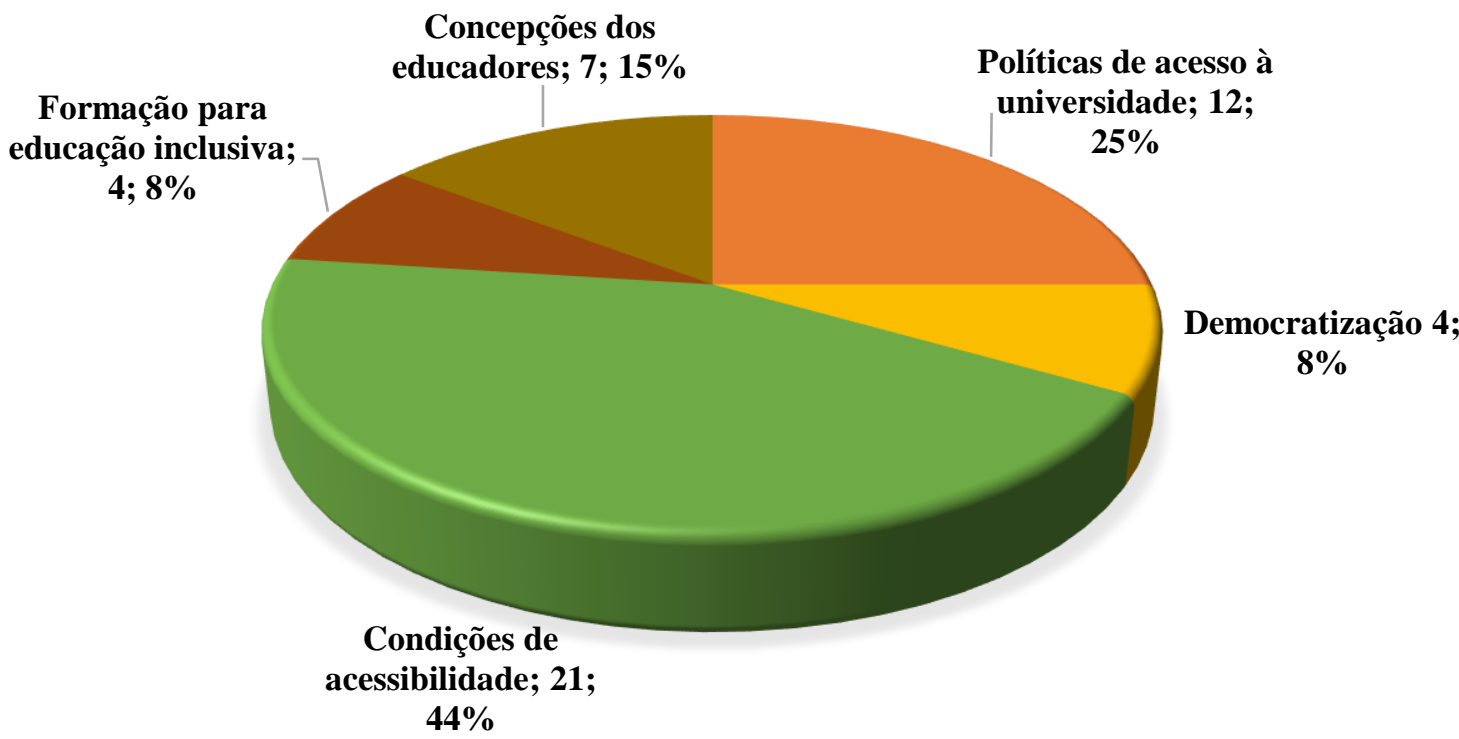

Fonte: autoras.

Para a categoria "Políticas de acesso à universidade" foram encontrados 12 artigos (25\%). Esses estudos discutem as políticas de inclusão nas universidades que estabelecem o critério de perfil socioeconômico dos estudantes. Dentre essas pesquisas, seis estão voltadas especificamente à análise do Prouni. Os trabalhos que abordam as políticas afirmativas a partir do perfil socioeconômico perpassaram análises das seguintes questões: política afirmativa sobre inclusão social que prevê pontuação adicional aos egressos da escola pública nas IES públicas, avaliação de desempenho de bolsistas e análise das contradições entre inclusão/exclusão a partir de tais políticas geradas no espaço acadêmico. As pesquisas voltadas ao Prouni trazem análises sobre inserção universitária, impacto institucional e social gerado pelo programa e efetividade do mesmo a partir da ótica de seus beneficiários (WINTHER; GOLGHER, 2010; AMARAL; OLIVEIRA, 2011; SARAIVA; NUNES, 2011; MATOS et al., 2012; SANTOS, 2012; FELICETTI; 
CABRERA; MOROSSINI, 2014; ALMEIDA; ERNICA, 2015; GRINER; SAMPAIO; SAMPAIO, 2015; FONTELE; CRISÓSTOMO, 2016; OLIVEIRA; SILVA, 2017; WAINER; MELGUIZO, 2017).

Essas análises constatam maior inserção após criação dos programas sociais de inclusão no ensino superior. Alguns autores estabelecem, ainda, a relação de que a ampliação da participação no ensino superior de grupos historicamente excluídos (por etnia ou por renda) não representou comprometimento da qualidade de ensino nas universidades. Nessa perspectiva, destaca-se a defesa da vinculação entre as políticas inclusivas no ensino superior, a melhoria da qualidade de ensino básico e a ampliação dos direitos sociais (WINTHER; GOLGHER, 2010; MATOS et al., 2012; ALMEIDA; ERNICA, 2015; OLIVEIRA; SILVA, 2017; WAINER; MELGUIZO, 2017).

No entanto, apontam-se alguns indicadores de que a democratização é um processo em construção no qual a relativa inclusão desses grupos se deu sem alterar a manutenção do padrão tradicional do ensino superior brasileiro. Assim, alguns marcadores (o maior quantitativo de IES privadas, a maior utilização de políticas afirmativas voltadas ao ensino particular, a concentração de beneficiários das políticas afirmativas nos cursos de menor prestígio social) evidenciam que o ensino superior ainda se apresenta como espaço de reprodução das desigualdades econômicas, sociais, culturais e políticas do país (ALMEIDA; ERNICA, 2015; OLIVEIRA; SILVA, 2017).

Nesse contexto, alguns estudos constatam que os beneficiados pelo Prouni pertencem a grupos de cor, classe social, renda e origem escolar pouco representativos no ensino superior. Tais perspectivas apontam que o programa tem demonstrado eficácia pela baixa taxa de evasão e por propiciar aos egressos novas trajetórias profissionais. Porém, também mostram que há críticas que incidem sobre a necessidade de ajustes nas políticas públicas educacionais. Tais conclusões indicam que a despeito de atingir grande número de brasileiros, essa iniciativa mascara a necessidade de investimentos substanciais em educação pública e de qualidade (AMARAL; OLIVEIRA, 2011; SANTOS, 2012; FONTELE; CRISÓSTOMO, 2016; SARAIVA; NUNES, 2011).

Assim, as análises se encontram imersas em um campo antagônico: de um lado, enxergam o Prouni unicamente voltado ao atendimento de demandas da lógica capitalista; de outro, defendem ser urgente uma reparação histórica a segmentos excluídos do nível superior de ensino.

A temática de "democratização do ensino superior" apresenta uma perspectiva crítica e 
ampliada do processo histórico, social e político de acesso a esse segmento de ensino no país. Esses estudos versam sobre a problematização da educação como bem público e como mercadoria, refletida nas contradições das políticas direcionadas ao ensino superior; sobre o cenário de ampliação de acesso e política de inclusão; acerca da promoção de equidade e inclusão de segmentos excluídos; e sobre os processos (excludentes) de inclusão no contexto do capitalismo (NEVES; RAIZER; FACHINETTO, 2007; BROSTOLIN; CRUZ, 2010; SOBRINHO, 2010; NUNES; NEIRA, 2014).

Com um resgate histórico da origem do conceito de universidade na idade média europeia - tomada como referência de um espaço aberto para os saberes universais -, esses artigos discutem a questão da democratização do espaço acadêmico, apontando o sentido original do papel destas instituições enquanto lócus de diferentes saberes, representativos da diversidade sociocultural da humanidade. Assim, a perspectiva da educação como bem público, e não negócio, impõe à educação superior a necessidade de recuperar o sentido de instituição referenciada ao público e ao social, em oposição à lógica de organização mercantil (BROSTOLIN; CRUZ, 2010; SOBRINHO, 2010).

Dessa forma, a partir da análise de que o aumento de vagas ofertadas pelo setor privado atende a uma lógica própria de gestão das IES privadas, os autores trazem a reflexão de que os processos de inclusão estruturados nas identidades de consumo e performatividade, baseados no neoliberalismo, reforçam a diferença por meio de processos sutis de exclusão. Nesse sentido, as análises apontam que os projetos de ensino superior para segmentos historicamente excluídos correm o risco da superficialidade, ao centrarem suas ações exclusivamente no acesso aos ambientes acadêmicos, negligenciando os processos mais amplos de busca de autonomia desses segmentos (NEVES; RAIZER; FACHINETTO, 2007; BROSTOLIN; CRUZ, 2010; NUNES; NEIRA, 2014).

Assumindo a defesa de que democratização não se restringe à expansão quantitativa sendo, portanto, imprescindível que se cumpra o princípio de qualidade pública e equidade -, os estudos apontam que as transformações do ensino superior, comprometidas com tais princípios, devem necessariamente estar vinculadas às mudanças estruturais de todo o sistema educativo e da sociedade; apontamentos que indicam a importância do caráter sistêmico das políticas públicas para o setor. As análises também ressaltam que a despeito da tendência dos processos 
globalizantes de homogeneização política, cultural e de mercado, o ensino superior (enquanto território cultural híbrido) tanto pode fortalecer certos grupos, como potencializar resistências (NEVES; RAIZER; FACHINETTO, 2007; SOBRINHO, 2010; NUNES; NEIRA, 2014).

Frente ao exposto, os artigos que abordam a democratização e as políticas de acesso à Universidade trazem contribuições que podem ser tomadas como questões que tangenciam o núcleo da temática em voga, subsidiando, porém, uma perspectiva ampliada de democratização do espaço acadêmico. Por esse motivo, mesmo não representando a temática mais explorada, são pontuados anteriormente aos temas nucleares subsequentes.

Por sua vez, a temática "Condições de acessibilidade" para pessoas com deficiência no ensino superior foi contemplada por uma incidência maior de artigos (21 ou 44\%). Em linhas gerais, quinze artigos analisados nessa temática discutem políticas, dispositivos legais, ações institucionais e produção científica, buscando verificar barreiras e facilitadores do processo de inclusão a partir da visão dos universitários com deficiência, dos serviços de apoio institucionais, coordenadores de cursos, gestores, bem como a partir de análises de pesquisas e indicadores educacionais (FERREIRA, 2007; SIQUEIRA; SANTANA, 2010; DUARTE et al., 2013; CASTRO; ALMEIDA, 2014; SILVA, 2014; CANTORANI; PILATTI, 2015; MARTINS; LEITE; LACERDA, 2015; SANTOS et al., 2015; CALHEIROS; FUMES, 2016; CIANTELLI; LEITE, 2016; FERNANDES; OLIVEIRA; ALMEIDA, 2016; OLIVEIRA et al., 2016; CABRAL; MELO, 2017; PEREIRA; BIZELLI; LEITE, 2017; PLETSCH; LEITE, 2017).

Ainda nessa temática, seis artigos especificam o tipo de deficiência tratado nas pesquisas. Esses trabalhos discutem os desafios, vivências e estratégias desenvolvidas por universitários com determinadas deficiências para permanecerem no ensino superior, e ressaltam a importância de apoios e recursos no atendimento adequado às especificidades apresentadas por esses estudantes. Assim, três pesquisas estão voltadas para a deficiência auditiva (MANENTE; RODRIGUES; PALAMIM, 2007; FRANCO, 2009; BISOL et al., 2010), uma refere-se à deficiência visual (FERNANDES; COSTA, 2015) e duas mencionam as deficiências visual, física, múltipla e auditiva (MOREIRA; BOLSANELLO; SEGER, 2011; GUERREIRO; ALMEIDA; SILVA FILHO, 2014).

A análise dessa temática nos permite verificar que as pesquisas deflagram o reconhecimento de significativos avanços nas últimas décadas, no que concerne aos direitos educacionais da pessoa com deficiência. Assim, esses estudos apontam que mesmo sob a égide 
da bandeira inclusiva, existe hoje um grande hiato entre a realidade vivenciada no contexto da formação acadêmica, em relação à efetivação do acesso e permanência dos estudantes com deficiência, e as determinações referendadas pelos dispositivos legais (SIQUEIRA; SANTANA, 2010; DUARTE et al., 2013; CASTRO; ALMEIDA, 2014; FERNANDES; OLIVEIRA; ALMEIDA, 2016).

As pesquisas, por sua vez, que analisam os censos escolares, fazem referência à indicação da evolução do número de matrículas de estudantes com deficiência no ensino superior, e discutem o fato de que os índices quantitativos precisam estar associados à oportunidade de acesso a um ensino de qualidade. Essas análises ressaltam que apesar da evolução em termos numéricos, o quadro de matrícula da pessoa com deficiência no ensino superior ainda representa uma parcela mínima da população com deficiência, apontando, assim, a presença inexpressiva de estudantes com deficiência no ensino superior quando comparado aos números de matrículas no ensino fundamental. Dessa forma, o reconhecimento da importância do aparato legal implica na necessidade de efetivar a operacionalização dessas leis (DUARTE et al., 2013; MARTINS; LEITE; LACERDA, 2015).

A análise das referidas produções constata, no âmbito da universidade, o pouco conhecimento disponível sobre o tema da diversidade e da inclusão, tanto no que se refere à prática inclusiva em si, como diante das normalizações e legislações. Assim, o desconhecimento das universidades possibilita a posição equivocada de negligenciar seus deveres legais, restringindo o entendimento de acessibilidade ao contexto de ingresso, como se a reserva de vagas para estudantes com deficiência fosse em si a referida inclusão social e educativa desses sujeitos (OLIVEIRA et al., 2016; FERNANDES; OLIVEIRA; ALMEIDA, 2016). Frente a tal constatação, é uníssona a defesa de que a inclusão de pessoas com deficiência no ensino superior refere-se a tudo o que envolve o sujeito em suas relações cotidianas no processo de formação, sendo, assim, indispensável que a universidade ofereça uma educação de qualidade, em cumprimento a um dever do estado de implementar ações que favoreçam não apenas o ingresso, como a permanência e saída dos estudantes com deficiência do ensino superior (SIQUEIRA; SANTANA, 2010).

No contexto desse entendimento, os estudos apontam que promover a inclusão nesse segmento de ensino representa um desafio pelo qual perpassam diversas dificuldades: romper as barreiras existentes, sobretudo, as atitudinais, por meio de ações que promovam a 
sensibilização da comunidade universitária e a desconstrução de crenças, preconceitos e identidades institucionais pautadas unicamente na meritocracia; o respeito às diferenças; e a ética da inclusão.

Para além da sensibilização da comunidade acadêmica e do combate à desinformação, identifica-se uma ampla necessidade de ações voltadas à formação continuada de docente e servidores, à aquisição de equipamentos e materiais pedagógicos apropriados, à promoção das condições de acessibilidade (arquitetônica, comunicacional e pedagógica) e ao fortalecimento dos núcleos de acessibilidade (DUARTE et al., 2013; CASTRO; ALMEIDA, 2014; CIANTELLI; LEITE, 2016; FERNANDES; OLIVEIRA; ALMEIDA, 2016).

Outro aspecto relevante abordado nos trabalhos que discutem condições de acessibilidade no ensino superior chama atenção para a compatibilidade entre o real aprendizado do estudante e o diploma a ser concedido pela IES, no sentido de que a habilitação profissional seja coerente à proposta de formação. Assim, o diálogo entre as universidades e os conselhos profissionais surge como possibilidade de auxílio na seleção de aprendizagens a serem adaptadas, alteradas ou substituídas, no atendimento às especificidades que se fizerem presentes.

Considerando a responsabilidade das IES em prover meios pedagógicos adaptativos para que os estudantes acessem, permaneçam e concluam a formação escolhida, pontua-se a necessidade e coerência de que o diálogo entre IES, Ministério da Educação, conselhos profissionais e sociedade civil possibilite avaliar quais aprendizagens são necessárias e podem ser adaptadas para questões que considerem o contexto micro e/ou macro regionais (SILVA, 2014; FERREIRA, 2007).

Os artigos que analisam a acessibilidade especificando o tipo de deficiência envolvida no estudo, mencionam, em geral, as vivências e estratégias de permanência no ensino superior desenvolvidas pelos estudantes. Destacam, a importância de relacionar os fatores internos do estudante (psicoafetivos, atitudes, crenças e valores) com a adequação do meio (estruturais e operacionais) no processo de permanência dos estudantes com deficiência. Cabe ressaltar que esses estudos se referem à pesquisa com universitários com deficiência física, visual, auditiva e intelectual, e puderam verificar que o nível de conhecimento dos estudantes sobre a legislação e determinações inclusivas está relacionado à capacidade de avaliar criticamente a adequação 
das condições institucionais de acessibilidade. Assim, os dados mostram que os estudantes que têm conhecimento de seus direitos tendem a apresentar menor nível de satisfação com a estrutura institucional (MOREIRA; BOLSANELLO; SEGER, 2011; GUERREIRO; ALMEIDA; FILHO, 2014).

Considerando que ainda é baixo o acesso e a participação dos deficientes auditivos no ensino superior, os estudos que descrevem o desafio da adaptação dos sujeitos surdos a um universo majoritariamente ouvinte relatam que esses estudantes têm buscado os recursos de que precisam de maneira independente e/ou a partir da ajuda de colegas. Porém, esses trabalhos pontuam que apesar dessa experiência sobrecarregar o estudante cognitiva, emocional e socialmente, ela possibilita novos olhares sobre as vivências anteriores, quando restritas à comunidade surda. Ressaltam, portanto, que se puderem contar com o apoio da instituição de ensino, os jovens surdos poderão se beneficiar da formação em um contexto de diversidade e heterogeneidade (MANENTE; RODRIGUES; PALAMIN, 2007; FRANCO, 2009; BISOL et al., 2010).

No que tange às questões atinentes à "Formação voltada à educação inclusiva", encontramos quatro trabalhos desenvolvidos ( $8 \%$ do total). A temática abordada trouxe como foco a formação de professores universitários para atendimento às pessoas com deficiência visual, aspectos da formação e prática de tradutores intérpretes de Língua Brasileira de Sinais, a perspectiva de licenciandos em relação à formação para educação inclusiva e a elaboração de um objeto digital de aprendizagem para estudantes com deficiência auditiva (REIS; EUFRASIO; BAZON, 2010; LACERDA; GURGEL, 2011; OLIVEIRA et al., 2011; BISOL; VALENTINI, 2012).

Esses trabalhos sobre a temática destacam a formação inicial e continuada no processo premente de qualificação dos docentes para atuação alinhada às políticas educacionais inclusivas. Nessa perspectiva, as políticas de democratização e expansão do ensino superior brasileiro inauguram mudanças, em que um espaço historicamente elitista e meritocrático passa para um contexto de convivência com a diversidade de uma população cada vez mais heterogênea, implicando, necessariamente, na revisão de velhos conceitos de normalidade e padrões de aprendizagem. Assim, é ressaltada a relevância da discussão acerca da educação inclusiva na formação inicial frente à verificação da carência de conhecimento sobre a temática nos cursos de licenciatura em Biologia, Física e Química, assim como as dificuldades do processo de inclusão no ensino superior evidenciam a necessidade de formação continuada dos docentes 
que atuam nesse segmento, seja em função das lacunas de formação, ou mesmo da postura adotada em sala de aula (REIS; EUFRÁSIO; BAZON, 2010; OLIVEIRA et al., 2011; BISOL; VALENTINI, 2012).

Nesse contexto, ao analisarem a formação de licenciatura em Ciências Biológicas de professores universitários para atendimento de estudantes com deficiência visual, Reis, Eufrásio e Bazon (2010) pontuam a pouca incidência de docentes que realizam adaptação de material didático, gerando dificuldade no processo de aprendizagem desses estudantes pela desconsideração de seu referencial perceptual. O mesmo estudo ressalta que a concepção dos docentes acerca da inclusão social e escolar esteve circunscrita à garantia de matrícula, acesso ao material didático adaptado e à estrutura física, apontando, assim, a perspectiva de inclusão social e escolar restrita à deficiência (REIS; EUFRÁSIO; BAZON, 2010).

Nessa perspectiva, os estudos afirmam a questão da formação docente como essencial na instrumentalização para lidar com as diferentes formas de aprender, e ressaltam a necessidade de promover uma mudança de atitudes. Pontuam, portanto, que além da informação, é fundamental ressignificar a relação com o outro diferente (seja diferença física, intelectual, religiosa, étnica, socioeconômica, entre outras), em um cenário permeado de estereótipos, mitos e preconceitos (REIS; EUFRÁSIO; BAZON, 2010; BISOL; VALENTINI, 2012).

Cabe ainda mencionar que o campo de investigação sobre formação para educação inclusiva no ensino superior, envolve o interesse pela atuação de outros profissionais, além dos docentes. Assim, um cenário menos excludente abre espaço tanto para a diversidade dos universitários, quanto para de profissionais que atuam junto ao docente na efetivação de práticas de educação inclusiva, dentre estes, o tradutor intérprete de Libras.

Enquanto agente favorecedor da construção do conhecimento pela mediação das relações de comunicação entre surdos e ouvintes, as reflexões apontam a importância de se ter uma formação de qualidade, uma vez que além do conhecimento linguístico e contato com a comunidade surda, a interpretação exige conhecimento de mundo, escolhas léxicas e de sentido para uma atuação adequada do tradutor intérprete ao processo de aprendizagem do estudante (LACERDA; GURGEL, 2011).

A abordagem da temática "Concepções dos docentes" sobre inclusão de universitários com deficiência esteve presente em sete pesquisas (15\%). Os estudos compreenderam análises 
das concepções, demandas e temores apontados pelos docentes em relação ao processo de formação de estudantes com deficiência, perpassando questões didático-pedagógica, avaliativa e estrutura organizacional. As dificuldades apontadas perpassaram as barreiras pedagógicas, carência de material didático adequado, necessidade de implantação/fortalecimento dos serviços de apoio e sentimento de despreparo vivenciado pelos docentes. Verificou-se, ainda, que as percepções favoráveis estiveram condicionadas por fatores ideológicos e instrumentais (ÁVILA; TACHIBANA; VAISBERG, 2008; VILELA-RIBEIRO; BENITE, 2010; PEREIRA; SANTOS; SILVA, 2011; SILVA; CYMROT; D'ANTINO, 2012; ANTUNES et al., 2013; REGIANI; MÓL, 2013; PIECZKOWSKI, 2016).

Nesse contexto, as pesquisas que se dedicaram a escutar os docentes, propiciando que estes pudessem expressar seus temores, ideias e perspectivas sobre inclusão de pessoas com deficiência no ensino superior, apontam que a educação inclusiva demanda a reconstrução do sistema de ensino no sentido de transpor diversas barreiras pedagógicas. A falta de conhecimento sobre metodologia de ensino, material didático adequado e a percepção do próprio despreparo para a interação com os estudantes que apresentam necessidades específicas são apontados pelos docentes como principais causas das dificuldades de formação acadêmica dos universitários com deficiência.

Para além da necessidade de quebra de barreiras arquitetônicas, os estudos ressaltam a superação das barreiras atitudinais, como maior dificuldade de enfrentamento, no que concerne à desconstrução de preconceitos em relação à diferença (SILVA; CYMROT; D' ANTINO, 2012; REGIANI; MÓL, 2013). Contudo, trabalhos que analisam as concepções sobre a inclusão de estudantes com deficiência no ensino superior apontam aspectos que traduzem preocupação em atender as demandas das políticas de inclusão, por parte dos gestores, e sensibilidade e abertura dos docentes para responder ao paradigma inclusivo nesse nível de ensino (PEREIRA; SANTOS; SILVA, 2011; ANTUNES et al., 2013).

Abordando o processo de avaliação da aprendizagem de estudantes com deficiência no ensino superior na perspectiva da educação inclusiva, Pieczkowski (2016) investiga as inquietações docentes frente a esse desafio. Ao analisar a presença de estudantes com deficiência como potencializadora de conflitos inerentes à prática avaliativa, o estudo problematiza os efeitos que a diferença produz na docência e na estrutura rígida do sistema 
educativo. A reflexão sinaliza a contradição de que a diferença provoca inquietações que mobilizam novos olhares sobre a história da universidade e sobre as práticas de avaliação, tomadas em seu caráter, eminentemente, classificatório e seletivo, enquanto a perspectiva inclusiva exige subjetividades solidárias (PIECZKOWSKI, 2016).

A pesquisa identifica na fala de alguns docentes a percepção de uma inclusão ambivalente, com fragilidades e limitações. Para a autora, a ambivalência da inclusão se expressa em uma escola inclusiva, pautada em princípios de temporalidade diferenciada, solidariedade e respeito à diferença; porém, essa mesma escola, se organiza com base em princípios de homogeneidade sólida, com tempo e espaço fixo pensados de maneira linear (PIECZKOWSKI, 2016).

Nessa perspectiva, o antagonismo se manifesta num discurso do estado que demanda instituições e professores inclusivos, ao mesmo tempo que as avaliações das universidades são padronizadas por indicadores, baseados nos resultados. Assim, apontando a necessidade de problematizar os próprios currículos dos cursos superiores, o artigo destaca os conflitos docentes frente às concepções dominantes de avaliação e o apelo aos processos mobilizados pela perspectiva da educação inclusiva (PIECZKOWSKI, 2016).

\section{Considerações Finais}

O levantamento, sistematização e análise da produção do conhecimento acerca da inclusão no ensino superior possibilitou uma reflexão quanto ao cenário da atenção dispensada às questões atinentes à inclusão de sujeitos historicamente excluídos do ensino superior, entre esses, foco privilegiado do estudo, as pessoas com deficiência.

Assim, frente à complexidade dos elementos relacionados às ações educativas de inclusão, verificamos que as políticas afirmativas, de modo geral, se inscrevem em um processo de rompimento com a lógica excludente que naturalizou o espaço universitário como seletivo e meritocrático. Institui, portanto, no contexto acadêmico o desafio do convívio com a diferença, não somente socioeconômica e ética, mas, inclusive, a diferença relacionada às características físicas, sensoriais e intelectuais distintivas.

Frente ao exposto, em uma perspectiva de contextualização, a articulação dos estudos 
que discutem a democratização do ensino superior e as políticas e programas de inclusão instituídas com base no contexto socioeconômico, nos permite verificar que os trabalhos voltados aos aspectos pontuais tendem a uma análise positiva, marcada pelo reconhecimento de avanços em tais ações. Porém, as pesquisas que problematizam questões de ordem histórica, política e social, trazem uma análise crítica na qual apontam limites e contradições no processo de democratização do ensino superior.

Nesse contexto, as pesquisas caracterizadas como nucleares à temática trazem como foco a questão da acessibilidade para as pessoas com deficiência, a formação para educação inclusiva e as concepções das pessoas envolvidas no processo de formação. Tais estudos indicam que os desafios e caminhos buscados pelas universidades para garantir a participação desses sujeitos nas atividades acadêmicas estão sendo construídos e transformados à medida que se avança no conhecimento da realidade e das necessidades das pessoas com deficiência. Apontam, no entanto, a necessidade de reconstrução do sistema de ensino superior para superação de barreiras e a necessidade de investimento em ações que possam promover uma cultura institucional verdadeiramente inclusiva, que problematize o preconceito e favoreça autonomia e cidadania.

Cabe, ainda, mencionar a observação de que as pesquisas analisadas na categoria de condições de acessibilidade, que especificam tipo de deficiência no ensino superior, referem-se às deficiências físicas e sensoriais. Chama atenção, no entanto, o fato de não ter sido encontrado artigo que discutisse a deficiência intelectual, os transtornos globais do desenvolvimento e as altas habilidades ou superdotação.

Dessa forma, o contexto das pesquisas remete à relevância de se empreender estudos no sentido de contribuir com a produção de pensamento crítico sobre a temática, uma vez que desvelar os desafios em relação à formação universitária das pessoas com deficiência representa assumir a defesa de uma formação de qualidade, enquanto espaço de apropriação de conhecimento e desenvolvimento humano.

\section{Referências}

ALMEIDA, A. M. F.; ERNICA, M. Inclusão e segmentação social no ensino superior público no Estado de São Paulo (1990-2012). Educação \& Sociedade, Campinas, v.36, n.130, p.63-83, 2015. 
DOI: http://dx.doi.org/10.1590/ES0101-73302015139672. Disponível em: http://ref.scielo.org/sx5w28. Acesso em: 04 ago. 2018.

AMARAL, D. P.; OLIVEIRA, F. B. DE. O ProUni e a conclusão do ensino superior: questões introdutórias sobre os egressos do programa na zona oeste do Rio de Janeiro. Ensaio: Avaliação e Políticas Públicas em Educação, Rio de Janeiro, v.19, n.70, p.21-42, 2011. DOI:

http://dx.doi.org/10.1590/S0104-40362011000100003. Disponível em: http://ref.scielo.org/q55h66. Acesso em: 04 ago. 2018.

ANSAY, N. N. A inclusão de alunos surdos do ensino superior. Revista do Núcleo de Estudos e Pesquisas Interdisciplinares em Musicoterapia, Curitiba, v.1, p.1-141, 2010. Disponível em: http://periodicos.unespar.edu.br/index.php/incantare/article/view/174. Acesso em: 04 ago. 2018.

ANTUNES, A. P. et al. Inclusão no ensino superior: percepções de professores em uma universidade portuguesa. Psicologia em Pesquisa, Juiz de Fora, v.7, n.2, p.140-150, 2013. Disponível em: http://pepsic.bvsalud.org/scielo.php?script=sci_arttext\&pid=S198212472013000200002. Acesso em: 04 ago. 2018.

ÁVILA, C. F.; TACHIBANA, M.; VAISBERG, T. M. J. A. Qual é o lugar do aluno com deficiência? o imaginário coletivo de professores sobre a inclusão escolar. Paidéia, Ribeirão Preto, v.18, n.39, p.155-164, 2008. DOI: http://dx.doi.org/10.1590/S0103-863X2008000100014. Disponível em: http://ref.scielo.org/6n8jfm. Acesso em: 04 ago. 2018.

BEYER, H. O. O projeto da educação inclusiva: perspectivas e princípios de implementação. In: MEYRELLES DE JESUS, D. et al. (Org.) Inclusão, práticas pedagógicas e práticas inclusivas. 3.ed. Porto Alegre: Mediação, 2011. p.75-81.

BISOL, C. A. et al. Estudantes surdos no ensino superior: reflexões sobre a inclusão. Cadernos de Pesquisa, São Paulo, v.40, n.139, p.147-172, 2010. DOI: http://dx.doi.org/10.1590/S010015742010000100008. Disponível em: http://ref.scielo.org/3wvn84. Acesso em: 04 ago. 2018.

BISOL, C. A.; VALENTINI, C. B. Desafios da inclusão: uma proposta para a qualificação de docentes no ensino superior via tecnologias digitais. Revista Portuguesa de Educação, Braga, v.25, n.2, p.263-280, 2012. Disponível em:

http://www.scielo.mec.pt/scielo.php?script=sci_arttext\&pid=S0871-91872012000200012. Acesso em: 04 ago. 2018.

BRASIL. Constituição (1988). Constituição da República Federativa do Brasil. Brasília: Senado Federal: Centro Gráfico, 1988.

BRASIL. Casa Civil. Lei no 8.069, de 13 de julho de 1990. Dispõe sobre o estatuto da criança e do adolescente e dá outras providências. Disponível em:

http://www.planalto.gov.br/ccivil_03/leis/l8069.htm. Acesso em: 04 mar. 2019. 
BRASIL. Ministério da Educação. Lei no 9.394, de 20 de dezembro de 1996. Estabelece as diretrizes e bases da educação nacional e dá outras providências. Disponível em: http://portal.mec.gov.br/seed/arquivos/pdf/tvescola/leis/lein9394.pdf. Acesso em: 04 ago. 2019.

BRASIL. Ministério da Educação. Lei no 010172, de 09 de janeiro de 2001. Aprova o plano nacional de educação e dá outras providências. Disponível em:

http://portal.mec.gov.br/arquivos/pdf/L10172.pdf. Acesso em: 04 ago. 2019.

BRASIL. Câmara dos Deputados. Decreto no 6.096, de 24 de abril de 2007. Dispõe sobre a educação especial, o atendimento educacional especializado e dá outras providências. Disponível em: http://www.planalto.gov.br/ccivil_03/_ato20072010/2007/decreto/d6096.htm. Acesso em: 04 ago. 2019.

BRASIL. Câmara dos Deputados. Decreto no 7.611, de 17 de novembro de 2011. Dispõe sobre a educação especial, o atendimento educacional especializado e dá outras providências. Disponível em: http://www2.camara.leg.br/legin/fed/decret/2011/decreto-7611-17novembro-2011-611788-publicacaooriginal-134270-pe.html. Acesso em: 04 ago. 2019.

BRASIL. Lei no 13.146, de 6 de julho de 2015. Institui a lei brasileira de inclusão da pessoa com deficiência (estatuto da pessoa com deficiência). Disponível em:

http://www.planalto.gov.br/ccivil_03/_ato2015-2018/2015/lei//13146.htm. Acesso em: 04 ago. 2019.

BRASIL. Câmara dos Deputados. Lei no 13.409, de 28 de dezembro de 2016. Altera a Lei no 12.711, de 29 de agosto de 2012, para dispor sobre a reserva de vagas para pessoas com deficiência nos cursos técnico de nível médio e superior das instituições federais de ensino. Disponível em: http://www.planalto.gov.br/ccivil_03/_ato2015-2018/2016/lei/L13409.htm. Acesso em: 04 ago. 2019.

BRASIL. Ministério da Educação. Instituto Nacional de Estudos e Pesquisas Educacionais Anísio Teixeira (INEP). Censo escolar da Educação Básica 2016, Brasília. Disponível em: http://download.inep.gov.br/educacao_basica/censo_escolar/notas_estatisticas/2017/notas_e statisticas_censo_escolar_da_educacao_basica_2016.pdf. Acesso em: 04 ago. 2019.

BROSTOLIN, M. R.; CRUZ, S. F. Educação e sustentabilidade: o porvir dos povos indígenas no ensino superior em Mato Grosso do Sul. Interações, Campo Grande, v.11, n.1, p.33-42, 2010. DOI: http://dx.doi.org/10.1590/S1518-70122010000100004. Disponível em: http://ref.scielo.org/5pnbf4. Acesso em: 04 ago. 2018.

CABRAL, L. S. A.; MELO, F. R. L. V. Entre a normatização e a legitimação do acesso, participação e formação do público-alvo da educação especial em instituições de ensino superior brasileiras. Educar em Revista, Curitiba, v.33, n.3 [especial], p.55-70, 2017. Disponível em: https://revistas.ufpr.br/educar/article/view/51046. Acesso em: 04 ago. 2018. 
CALHEIROS, D. S.; FUMES, N. L. F. A inclusão de universitários com deficiência em cursos de Educação Física na cidade de Maceió/AL. Avaliação, Campinas, v.21, n.2, p.523-539, 2016. DOI: http://dx.doi.org/10.1590/S1414-40772016000200011. Disponível em: http://ref.scielo.org/c8f4c5. Acesso em: 04 ago. 2018.

CANTORANI, J. R. H.; PILATTI, L. A. Acessibilidade na Universidade Tecnológica Federal do Paraná: análise a partir de relatórios do Inep e do olhar do gestor. Educar em Revista, Curitiba, n.57, p.171-189, 2015. DOI: http://dx.doi.org/10.1590/0104-4060.41363. Disponível em: http://ref.scielo.org/62ymwn.Acesso em: 04 ago. 2018.

CASTRO, S. F.; ALMEIDA, M. A. Ingresso e permanência de alunos com deficiência em universidades públicas brasileiras. Revista Brasileira de Educação Especial, Marília, v.20, n.2, p.179-194, 2014. DOI: http://dx.doi.org/10.1590/S1413-65382014000200003. Disponível em: http://ref.scielo.org/455k8d. Acesso em: 04 ago. 2018.

CIANTELLI, A. P. C.; LEITE, L. P. Ações exercidas pelos núcleos de acessibilidade nas universidades federais brasileiras. Revista Brasileira de Educação Especial, Marília, v.22, n.3, p.413-428, 2016. DOI: http://dx.doi.org/10.1590/S1413-65382216000300008. Disponível em: http://ref.scielo.org/rmrknb. Acesso em: 04 ago. 2018.

DUARTE, E. R. et al. Estudo de caso sobre a inclusão de alunos com deficiência no ensino superior. Revista Brasileira de Educação Especial, Marília, v.19, n.2, p.289-300, 2013. DOI: http://dx.doi.org/10.1590/S1413-65382013000200011. Disponível em: http://ref.scielo.org/ysrck9. Acesso em: 04 ago. 2018.

FELICETTI, V. L.; CABRERA, A. F.; MOROSINI, M. C. Aluno ProUni: impacto na instituçao de educação superior e na sociedade. Revista Iberoamericana de Educación Superior, Huixquilucan, México, v.5, n.13, p.21-39, 2014. DOI: https://doi.org/10.1016/S2007-2872(14)71951-1. Disponível em: https://www.sciencedirect.com/science/article/pii/S2007287214719511\#!. Acesso em: 04 ago. 2018.

FERNANDES, A. C. R.; OLIVEIRA, M. C. S. L.; ALMEIDA, L. S. Inclusão de estudantes com deficiências na universidade: estudo em uma universidade portuguesa. Psicologia Escolar e Educacional, Maringá, v.20, n.3, p.483-492, 2016. DOI: http://dx.doi.org/10.1590/21753539201502031024. Disponível em: http://ref.scielo.org/737594. Acesso em: 04 ago. 2018.

FERNANDES, W. L.; COSTA, C. S. L. Possibilidades da tutoria de pares para estudantes com deficiência visual no ensino técnico e superior. Revista Brasileira de Educação Especial, Marília, v.21, n.1, p.39-56, 2015. DOI: http://dx.doi.org/10.1590/S1413-65382115000100004. Disponível em: http://ref.scielo.org/ks9yvn.Acesso em: 04 ago. 2018.

FERREIRA, N. S. A. As pesquisas denominadas "Estado da Arte". Educação e Sociedade, Campinas, v.23, n.79, p.257-272, 2002. DOI: http://dx.doi.org/10.1590/S010173302002000300013. Disponível em: http://ref.scielo.org/ddydfk. Acesso em: 04 ago. 2018. 
FERREIRA, S. L. Ingresso, permanência e competência: uma realidade possível para universitários com necessidades educacionais especiais. Revista Brasileira de Educação Especial, Marília, v.13, n.1, p.43-60, 2007. DOI: http://dx.doi.org/10.1590/S141365382007000100004. Disponível em: http://ref.scielo.org/7b4b44. Acesso em: 04 ago. 2018.

FONTELE, T. L. L.; CRISÓSTOMO, V. L. Prouni: pontos controversos sob a análise de alunos bolsistas. Avaliação, Campinas, v.21, n.3, p.739-765, 2016. DOI:

http://dx.doi.org/10.1590/S1414-40772016000300005. Disponível em: http://ref.scielo.org/ktr9cg. Acesso em: 04 ago. 2018.

FRANCO, M. Educação superior bilíngue para surdos: o sentido da política inclusiva como espaço da liberdade: primeiras aproximações. Revista Brasileira de Educação Especial, Marília, v.15, n.1, p.15-30, 2009. DOI: http://dx.doi.org/10.1590/S1413-65382009000100003. Disponível em: http://ref.scielo.org/xcz94s. Acesso em: 04 ago. 2018.

GOMES, C.; BAZON, F. V.M.; LOZANO, D. Atuação e concepções in/exclusivas de professores regulares dos municípios de Alfenas e Araras. Educação Unisinos, São Leopoldo, v.19, n.2, p.243-251, 2015. Disponível em:

http://revistas.unisinos.br/index.php/educacao/article/view/edu.2015.192.08. Acesso em: 04 ago. 2018.

GRINER, A.; SAMPAIO, L. M. B.; SAMPAIO, R. M. B. A política afirmativa "Argumento de Inclusão" como forma de acesso à universidade pública: o caso da Universidade Federal do Rio Grande do Norte. Revista de Administração Pública, Rio de Janeiro, v.49, n.5, p.1291-1317, 2015. DOI: http://dx.doi.org/10.1590/0034-7612123593. Disponível em: http://ref.scielo.org/rc26qb. Acesso em: 04 ago. 2018.

GUERREIRO, E. M. B. R.; ALMEIDA, M. A.; SILVA FILHO, J. H. Avaliação da satisfação do aluno com deficiência no ensino superior. Avaliação, Campinas, v.19, n.1, p.31-60, 2014. DOI: http://dx.doi.org/10.1590/S1414-40772014000100003. Disponível em: http://ref.scielo.org/jv4r97. Acesso em: 04 ago. 2018.

LACERDA, C. B. F.; GURGEL, T. M. A. Perfil de tradutores-intérpretes de Libras (TILS) que atuam no ensino superior no Brasil. Revista Brasileira de Educação Especial, Marília, v.17, n.3, p.481496, 2011. DOI: http://dx.doi.org/10.1590/S1413-65382011000300009. Disponível em: http://ref.scielo.org/pbzyv6. Acesso em: 04 ago. 2018.

LIMA, T. C. S.; MIOTO, R. C. T. Procedimentos metodológicos na construção do conhecimento científico: a pesquisa bibliográfica. Revista Katálysis, Florianópolis, v.10, p.37-45, 2007. DOI: http://dx.doi.org/10.1590/S1414-49802007000300004. Disponível em: http://ref.scielo.org/psqp8q. Acesso em: 04 ago. 2018.

MANENTE, M. V.; RODRIGUES, O. M. P.R.; PALAMIM, M. E. G. Deficientes auditivos e escolaridade: fatores diferenciais que possibilitam o acesso ao ensino superior. Revista Brasileira de Educação Especial, Marília, v.13, n.1, p.27-42, 2007. DOI: 
http://dx.doi.org/10.1590/S1413-65382007000100003. Disponível em: http://ref.scielo.org/t22kc3. Acesso em: 04 ago. 2018.

MARTINS, D. A.; LEITE, L. P.; LACERDA, C. B. F. Políticas públicas para acesso de pessoas com deficiência ao ensino superior brasileiro: uma análise de indicadores educacionais. Ensaio: Avaliação e Políticas Públicas em Educação, Rio de Janeiro, v.23, n.89, p.984-1014, 2015. DOI: http://dx.doi.org/10.1590/S0104-40362015000400008. Disponível em: http://ref.scielo.org/nn7jgs. Acesso em: 04 ago. 2018.

MATOS, M. S. et al. O impacto do programa de inclusão social da Universidade de São Paulo no acesso de estudantes de escola pública ao ensino superior público gratuito. Revista Brasileira de Estudos Pedagógicos, Brasília, v.93, n.235, p.720-742, 2012. DOI:

http://dx.doi.org/10.1590/S2176-66812012000400010. Disponível em: http://ref.scielo.org/zb5k8r. Acesso em: 04 ago. 2018.

MICHELS, M. H.; GARCIA, R. M. C. Sistema educacional inclusivo: conceito e implicações na política educacional brasileira. Cadernos Cedes, Campinas, v.34, n.93, p.157-173, mai./ago. 2014. DOI: http://dx.doi.org/10.1590/S0101-32622014000200002. Disponível em: http://ref.scielo.org/zd3d79. Acesso em: 04 ago. 2018.

MINISTÉRIO DA EDUCAÇÃO. Secretária de Educação Continuada, Alfabetização, Diversidade e Inclusão. Política nacional de educação especial na perspectiva da educação inclusiva, 2008 Disponível em:

http://portal.mec.gov.br/index.php?option=com_docman\&view=download\&alias=16690politica-nacional-de-educacao-especial-na-perspectiva-da-educacao-inclusiva05122014\&Itemid=30192. Acesso em: 04 ago. 2019.

MOREIRA, L. C.; BOLSANELLO, M. A.; SEGER, R. G. Ingresso e permanência na universidade: alunos com deficiências em foco. Educar em Revista, Curitiba, n.41, p.125-143, 2011. DOI: http://dx.doi.org/10.1590/S0104-40602011000300009. Disponível em: http://ref.scielo.org/nnsvm3. Acesso em: 04 ago. 2018.

NASCIMENTO, F. F.; CRUZ, M. M.; BRAUN, P. Escolarização de pessoas com transtorno do espectro do autismo a partir da análise da produção científica disponível da Scielo-Brasil (20052015). Arquivos Analíticos de Políticas Educativas, Arizona, v.24, n.125, p.1-25, 2016. DOI: https://doi.org/10.14507/epaa.24.2515. Disponível em: https://epaa.asu.edu/ojs/article/view/2515. Acesso em: 04 ago. 2018.

NEVES, C. E. B.; RAIZER, L.; FACHINETTO, R. F. Acesso, expansão e equidade na educação superior: novos desafios para a política educacional brasileira. Sociologias, Porto Alegre, v.9, n.17, p.124-157, 2007. DOI: http://dx.doi.org/10.1590/S1517-45222007000100006. Disponível em: http://ref.scielo.org/3838dw. Acesso em: 04 ago. 2018.

NUNES, M. L. F.; NEIRA, M. G. Processos de inclusão excludente presentes no ensino superior privado. Educação \& Realidade, Porto Alegre, v.39, n.4, p.1209-1228, 2014. DOI: 
http://dx.doi.org/10.1590/S2175-62362014000400014. Disponível em: http://ref.scielo.org/4x69cs. Acesso em: 04 ago. 2018.

OLIVEIRA, A. S. R.; SILVA, I. R. Políticas de inclusão social no ensino superior brasileiro - um estudo sobre o perfil socioeconômico de estudantes nos anos 2010 a 2012. Educação em Revista, Belo Horizonte, n.33, p.1-28, 2017. DOI: http://dx.doi.org/10.1590/0102-4698153900. Disponível em: http://ref.scielo.org/xktkgg. Acesso em: 04 ago. 2018.

OLIVEIRA, M. L. et al. Educação inclusiva e a formação de professores de Ciências: o papel das universidades federais na capacitação dos futuros educadores. Ensaio, Belo Horizonte, v.13, n.3, p.99-117, 2011. DOI: http://dx.doi.org/10.1590/1983-21172011130307. Disponível em: http://ref.scielo.org/89f4fd. Acesso em: 04 ago. 2018.

OLIVEIRA, R. Q. et al. A inclusão de pessoas com necessidades especiais no ensino superior. Revista Brasileira de Educação Especial, Marília, v.22, n.2, p.299-314, 2016. DOI:

http://dx.doi.org/10.1590/S1413-65382216000200011. Disponível em: http://ref.scielo.org/kk9k8c. Acesso em: 04 ago. 2018.

ORRÚ, S. E. A inclusão menor: um ensaio inspirado na obra "Kafka", de Deleuze e Guatarri. Educação em Foco, Belo Horizonte, v.19, n.28, p.47-73, 2016. Disponível em: http://revista.uemg.br/index.php/educacaoemfoco/article/view/1197. Acesso em: 04 ago. 2018.

PEREIRA, C. E. C.; BIZELLI, J. L.; LEITE, L. P. Organizações de ensino superior: inclusão e ambiente de trabalho. Educação \& Sociedade, Campinas, v.38, n.138, p.99-115, 2017. DOI: http://dx.doi.org/10.1590/es0101-73302017151511. Disponível em: http://ref.scielo.org/b9zw7b. Acesso em: 04 ago. 2018.

PEREIRA, F. J. R.; SANTOS, S. R.; SILVA, C. C. Política de formação inclusiva: percepção de gestores sobre processo de mudanças em instituições de ensino superior. Revista Brasileira de Enfermagem, v.64, n.4, p.711-716, 2011. Disponível em:

http://www.scielo.br/pdf/reben/v64n4/a13v64n4.pdf. Acesso em: 04 ago. 2018.

PIECZKOWSKI, T. M. Z. Avaliação da aprendizagem de estudantes com deficiências na educação superior. Revista Brasileira de Estudos Pedagógicos, Brasília, v.97, n.247, p.583-601, 2016. DOI: http://dx.doi.org/10.1590/s2176-6681/269030614. Disponível em: http://ref.scielo.org/rsx2s8. Acesso em: 04 ago. 2018.

PLETSCH, M. D.; LEITE, L. P. Análise da produção científica sobre a inclusão no ensino superior brasileiro. Educar em Revista, Curitiba, v.33, n. 3 [especial], p.87-106, 2017. DOI: http://dx.doi.org/10.1590/0104-4060.51042. Disponível em: http://ref.scielo.org/v9tdy2. Acesso em: 04 ago. 2018.

REGIANI, A. M.; MÓL, G. S. Inclusão de uma aluna cega em um curso de licenciatura em Química. Ciência \& Educação, Bauru, v.19, n.1, p.123-134, 2013. DOI: 
http://dx.doi.org/10.1590/S1516-73132013000100009. Disponível em: http://ref.scielo.org/hvrk9f. Acesso em: 04 ago. 2018.

REIS, M. X.; EUFRÁSIO, D. A.; BAZON, F. V. M. A formação do professor para o ensino superior: prática docente com alunos com deficiência visual. Educação em Revista, Belo Horizonte, v.26, n.1, p.111-130, 2010. DOI: http://dx.doi.org/10.1590/S0102-46982010000100006. Disponível em: http://ref.scielo.org/jky427. Acesso em: 04 ago. 2018.

ROSSETTO, E. Sujeitos com deficiência no ensino superior: vozes e significados. 2009. 237f. Tese (Doutorado em Educação) - Faculdade de Educação, Universidade Federal do Rio Grande do Sul, Porto Alegre, 2009. Disponível em: https://lume.ufrgs.br/handle/10183/21375. Acesso em: 04 ago. 2018.

SANTOS, C. T. Ações afirmativas no ensino superior: análise do perfil socioeconômico e da experiência universitária de bolsistas do ProUni na PUC-Rio. Revista Brasileira de Estudos Pedagógicos, Brasília, v.93, n.235, p.770-790, 2012. DOI: http://dx.doi.org/10.1590/S217666812012000400012. Disponível em: http://ref.scielo.org/w7czhj. Acesso em: 04 ago. 2018.

SANTOS, E. et al. Inclusão no ensino superior: percepções dos estudantes com necessidades educativas especiais sobre o ingresso à universidade. Revista Portuguesa de Educação, Braga, v.28, n.2, p.251-270, 2015. Disponível em:

http://www.scielo.mec.pt/scielo.php?script=sci_arttext\&pid=S0871-91872015000200013. Acesso em: 04 ago. 2018.

SARAIVA, L. A. S.; NUNES, A. S. A efetividade de programas sociais de acesso à educação superior: o caso do ProUni. Revista de Administração Pública, Rio de Janeiro, v.45, n.4, p.941964, 2011. DOI: http://dx.doi.org/10.1590/S0034-76122011000400003. Disponível em: http://ref.scielo.org/ssktp9. Acesso em: 04 ago. 2018.

SAVIANI, D. Escola e democracia. 32.ed. Campinas: Autores Associados, 1999.

SAVIANI, D. A expansão do ensino superior no Brasil: mudanças e continuidades. Poíesis Pedagógica, Catalão, v.8, n.2, p.4-17, 2010. DOI: https://doi.org/10.5216/rpp.v8i2.14035. Disponível em: https://www.revistas.ufg.br/poiesis/article/view/14035. Acesso em: 04 ago. 2018.

SILVA, A. M.; CYMROT, R.; D'ANTINO, M. E. F. Demandas de docentes do ensino superior para a formação de alunos com deficiência. Revista Brasileira de Estudos Pedagógicos, Brasília, v.93, n.235, p.667-697, 2012. Disponível em: http://www.scielo.br/pdf/rbeped/v93n235/08.pdf. Acesso em: 04 ago. 2018.

SILVA, J. O. Ações inclusivas no ensino superior brasileiro. Revista Brasileira de Estudos Pedagógicos, Brasília, v.95, n.240, p.414-430, 2014. Disponível em: http://www.scielo.br/pdf/rbeped/v95n240/09.pdf. Acesso em: 04 ago. 2018. 
SIQUEIRA, I. M.; SANTANA, C. S. Propostas de acessibilidade para a inclusão de pessoas com deficiências no ensino superior. Revista Brasileira de Educação Especial, Marília, v.16, n.1, p.127-136, 2010. DOI: http://dx.doi.org/10.1590/S1413-65382010000100010. Disponível em: http://ref.scielo.org/xvvhch. Acesso em: 04 ago. 2018.

SOBRINHO, J. D. Democratização, qualidade e crise da educação superior: faces da exclusão e limites da inclusão. Educação e Sociedade, Campinas, v.31, n.113, p.1223-1245, 2010. DOI: http://dx.doi.org/10.1590/S0101-73302010000400010. Disponível em: http://ref.scielo.org/9rmzy4. Acesso em: 04 ago. 2018.

VILELA-RIBEIRO, E. B.; BENITE, A. M. C. A educação inclusiva na percepção dos professores de química. Ciência \& Educação, Bauru, v.16, n.3, p.585-594, 2010. DOI: http://dx.doi.org/10.1590/S1516-73132010000300006. Disponível em: http://ref.scielo.org/8st852. Acesso em: 04 ago. 2018.

WAINER, J.; MELGUIZO, T. Políticas de inclusão no ensino superior: avaliação do desempenho dos alunos baseado no Enade de 2012 a 2014. Educação e Pesquisa, São Paulo, v.44, p.1-15, 2017. DOI: http://dx.doi.org/10.1590/s1517-9702201612162807. Disponível em: http://ref.scielo.org/48252h. Acesso em: 04 ago. 2018.

WINTHER, J. M.; GOLGHER, A. B. Uma investigação sobre a aplicação de bônus adicional como política de ação afirmativa na Universidade Federal de Minas Gerais (UFMG). Revista Brasileira de Estudos de População, São Paulo, v.27, n.2, p.333-359, 2010. DOI: http://dx.doi.org/10.1590/S0102-30982010000200007. Disponível em: http://ref.scielo.org/fksh3m. Acesso em: 04 ago. 2018.

Recebido em agosto 2019.

Aprovado em março 2020. 